\title{
Reasons for HIV Testing among Polish Patients-Community versus Country Data
}

\author{
Grzegorz Zabrzygraj1, Tomasz Mikuła2*, Magdalena Suchacz², Alicja Wiercińska-Drapało² \\ ${ }^{1}$ The Faculty of Health Sciences, Nursing Division, Medical University of Warsaw, Warsaw, Poland \\ ${ }^{2}$ Department of Hepatology and Acquired Immunodeficiencies, Medical University of Warsaw, Warsaw, \\ Poland \\ Email: ${ }^{*}$ tomasz.mikula6@wp.pl
}

Received 25 February 2014; revised 25 March 2014; accepted 11 April 2014

Copyright (C) 2014 by authors and Scientific Research Publishing Inc.

This work is licensed under the Creative Commons Attribution International License (CC BY).

http://creativecommons.org/licenses/by/4.0/

(c) $\underset{\mathrm{EY}}{\mathrm{O}}$ Open Access

\begin{abstract}
Background: Epidemiological data from each country can differ between cities and regions, for instance morbidity in HIV infection is four times higher in the south-west of Poland than in the east parts. Newly infected people are five times more often reported in the central part of our country than in the south-east. Methods: We assessed the main reasons for providing HIV tests among HIV-positive patients of The Department of Hepatology and Acquired Immunodeficiencies at the Medical University of Warsaw in comparison with the epidemiological situation in Poland. We designed a survey with baseline data and questions about the reasons for and place of HIV testing. Results: The main reason for HIV testing is risky sexual contacts, not intravenous drug use like several years ago. The main places where HIV infection is detected are hospitals, outpatients' clinics and consultative and diagnostic points (PCDs). Conclusion: Our results are not strictly the same like in our Polish national data or data of the PCD's but can give new epidemiologic insights into our patients' situation.
\end{abstract}

\section{Keywords}

Routes of HIV Transmission, HIV Testing, Consultative and Diagnostic Points

\section{Background}

In 1985 The Institute of Epidemiology of Polish National Institute of Hygiene (PNIH) has started registration of HIV-infected people and up to 30 April 2013 HIV infection was confirmed in 16,588 polish citizens [1]. Reported AIDS cases were 2908 and 1207 patients have died in this period [2]. Every day, 2 people in Poland get

\footnotetext{
${ }^{*}$ Corresponding author.
} 
positive HIV results. We observe an increasing percentage of HIV-infected women, approximately $25 \%$ in the last 3 years. The highest number of newly HIV-infected cases is in the Central and Western part of Poland. According to PNIH $41.7 \%$ acquired HIV infection through drugs injections, $22.9 \%$ and $18.3 \%$ for heterosexual and homosexual contacts respectively and $15 \%$ gave no information about the route of transmission. International standards and procedures introduced from 1994 enabled one to strongly reduce the risk of vertical transmission to $1 \%$ - 2\% [3]. Mostly young people are HIV-infected in Poland with $46 \%$ under twenty-nine and $7 \%$ younger than twenty. The largest group-up to 84\% of the HIV-infected-are between 20 - 49 years. From about three years ago we observed in Poland an increasing number of the HIV-infected older than 50 years which have a faster progression to AIDS and lower CD4 [4] [5]. Another change in recent years in the epidemiological situation in Poland is the increasing number of newly HIV-infected men who have sex with men (MSM) [6]. Among newly diagnosed late presented HIV-infected patients, about $8.9 \%$ are in the AIDS stage [7]. Important forms of early detection of HIV infection are consultative and diagnostic points (PCDs). The main source of funding for these institutions is the budget of the Ministry of Health with the National AIDS Center. Testing in the PCDs is anonymous and free of charge. During 2010 PCDs performed 26,188 HIV tests including 285 positive results [8]. According to Central Management Prison Service, about 20\% of newly HIV cases diagnosed are in prisons. According to UNAIDS data in Poland in 2007 about $0.58 \%$ of people between 15 - 49 years performed a test for HIV in the PCD [9]. It is estimated that in Poland, up to about $70 \%$ of people infected with HIV do not know they have the infection, which means that they are not included in the statistics. It is also concerned with the phenomenon of infection in the very young. Given the rapidly increasing number of HIV infection in other countries of Central and Eastern Europe, there is a potential risk of rapid spread of the epidemic in the region, which could have a direct impact on the situation in Poland. To learn more about patients of the clinic, we conducted a survey on the causes of testing for HIV. We also wanted to compare whether our patients differ from all of the national epidemiological reports.

\section{Methods}

Our study was carried out among HIV-infected patients admitted to The Department of Hepatology and Acquired Immunodeficiencies, the Medical University of Warsaw. Main inclusion criteria were: confirmed HIV infection (ELISA HIV antibody - twice positive confirmed with Western-Blot HIV-1), age over 18, compliance and good cooperation during the survey. We designed a questionnaire with baseline characteristics and 13 questions: gender, age, education, marital status, education, whether the person was offered HIV testing, number of provided tests, whether they have children, family and partner information, presence of HBV/HCV co-infections, place of testing, reasons and HIV infection duration. All patients were included with provided voluntary written, informed consent before the study. For statistic elaboration of results Statistica 9.0 has been used.

\section{Results}

We enrolled 52 HIV-infected patients of whom 42 were men. The youngest patient was 23, the oldest 72 years old. For baseline data characteristic see Table 1. The majority of our patients were young and unmarried. One of our observations was a relatively high percentage of people older than 50 years. Nearly half were older than 40 years. Medium and higher education represented $78 \%$ of patients and over half of the people were tested for HIV infection after a doctor's suggestion. The second most common answer was patients' self-decision. Almost half of patients have performed test for HIV only once. Among these patients risky sexual contacts were twice as frequent. About $25 \%$ of patients were MSM. The majority of patients were childless and more than $50 \%$ were not married. Some of the married patients decided to be childless because of the HIV infection. Among our patients one woman had a HIV-positive child. In our study more than $60 \%$ of patients informed at least one member of their family about their HIV infection. The majority had informed their sexual partner about their HIV infection as soon as they got the positive result. In our data 52\% were HIV/HCV within $92 \%$ of intravenous drug users. Almost half of the people analyzed had their first test for HIV in hospital. The second most common answer was outpatients' clinics (mostly dermatological) which could be connected with the dominant sexual route of HIV transmission in this group. The third place of testing people for HIV was PCDs. All patients were tested in PCD after self decision. The main reason for HIV testing among our patients was sexual contact. All of the analyzed patients were divided into three groups according HIV infection duration. In the group of HIV infected for less than 6 years we observed domination of sexual contacts as the route of transmission. Among than in- 
Table 1. Demographic and baseline characteristic of the study patients.

\begin{tabular}{|c|c|}
\hline Characteristics & \\
\hline Years of Age & $(\%)$ \\
\hline $20-29$ & 14.0 \\
\hline $30-39$ & 38.0 \\
\hline $40-49$ & 22.0 \\
\hline $50-59$ & 16.0 \\
\hline$>60$ & 10.0 \\
\hline Martial status & $(\%)$ \\
\hline Free & 58.0 \\
\hline Married & 20.0 \\
\hline Divorced & 16.0 \\
\hline Widows & 4.0 \\
\hline Separation & 2.0 \\
\hline Education & $(\%)$ \\
\hline Basic & 22.0 \\
\hline Medium & 48.0 \\
\hline Higher & 30.0 \\
\hline Who offered test for HIV? & $(\%)$ \\
\hline Doctor & 54.0 \\
\hline Self decision & 38.0 \\
\hline Sexual partner & 4.0 \\
\hline Friend & 4.0 \\
\hline Other & 0.0 \\
\hline Total number of HIV tests & $(\%)$ \\
\hline Once & 48.0 \\
\hline Twice & 24.0 \\
\hline More & 28.0 \\
\hline Number of children & $(\%)$ \\
\hline Childless & 56.0 \\
\hline Has been family informed? & $(\%)$ \\
\hline Yes & 66.0 \\
\hline Has patient's sexual partner been at once informed about HIV-positive result? & $(\%)$ \\
\hline Yes & 84.0 \\
\hline Coinfections & $(\%)$ \\
\hline $\mathrm{HCV}$ & 52.0 \\
\hline HBV and HCV & 8.0 \\
\hline No $\mathrm{HBV}$ or $\mathrm{HCV}$ & 36.0 \\
\hline Unknown & 4.0 \\
\hline Place of HIV testing & $(\%)$ \\
\hline Hospital & 48.0 \\
\hline PCD & 14.0 \\
\hline Blood donors & 6.0 \\
\hline Prison & 10.0 \\
\hline outpatients clinics & 22.0 \\
\hline
\end{tabular}




\begin{tabular}{|c|c|}
\hline Continued & \\
\hline Reasons of HIV testing & (n) \\
\hline Sexual contacts & 18 \\
\hline IDU & 14 \\
\hline Partner HIV infected & 6 \\
\hline Other & 14 \\
\hline HIV infection duration / routes of transmission & (n) \\
\hline$<6$ years & 21 \\
\hline Sexual contacts & 14 \\
\hline IDU & 7 \\
\hline 6 - 10 years & 7 \\
\hline Sexual contacts & 4 \\
\hline IDU & 3 \\
\hline$>10$ years & 24 \\
\hline Sexual contacts & 10 \\
\hline IDU & 14 \\
\hline
\end{tabular}

fected less than 10 but longer than 6 years sexual contacts and intravenous drug users (IDU) were nearly the same and for longer than 10 years IDUs was the most common route of transmission that is correlated with the epidemiological situation in Poland in most recent years.

\section{Discussion}

The diagnosis of infection with human immunodeficiency virus (HIV) is crucial for estimating HIV incidence in a population. Age, gender, marital status, education and routes of HIV transmission can give very important information about the community where we live. All of this data can be useful to solve or reduce a part of a community's problems. We analyzed more than $70 \%$ patients on combined antiretroviral treatment (cART) which were under our care. According to the data of the PNIH among HIV infected people in Poland about $25 \%$ are women so this is almost the same result as in our trial with 19.2\% of women [2]. A common feature of the epidemic situation around the world is the fact that HIV infection mainly affects young people. Nearly $40 \%$ of the HIV-infected in the world are between 15 and 24 years old. In Poland we have a similar situation with 7\% of all infections diagnosed below twenty years and $46 \%$ of all HIV infections affected people between 20 and 29 years of age. The dominant group, 84\% among HIV-infected and AIDS patients in Poland, are people from 20 to 49 years old [2]. In our study, we found the percentage of people over 50 years of age was $26 \%$. The aging of the population infected with HIV is connected with, on the one hand, reduced mortality among patients receiving antiretroviral therapy and on the other factors commonly used to improve sexual activity especially among men, which presented a significant proportion of our patients. The recent study shows the increase coincided with increased testing in the general population and increased prevalence in diagnostic testing of MSM suggesting important changes in the HIV epidemic in Poland with an increasing number of newly HIV infected in this group [10]. In the years 2004-2010 the percentage of MSM in the population PCD customers increased from $13.1 \%$ to 21.3\% [11]. In our trial almost 20\% patients were men who had sex with men (MSM) with domination diagnosed in outpatients' clinic. About $16 \%$ of our patients were divorced. Some did not find acceptance of a partner; others were not able to overcome the personal problems and decided to be single-especially when a partner was not HIV infected. It could be one of reasons why the majority of our patients were single. Among our married patients $67 \%$ had HIV infected partners. Some of these were looking for people with HIV, because in their opinion it is easier to create a long lasting relationship. We observed that $70 \%$ of our patients had a basic or medium education. This result is parallel with the country data confirms an elevated risk of HIV among undereducated young people [12]. In another publication, $69.8 \%$ of patients were poorly educated but living mostly in small cities and villages [13]. All of our patients are living in Warsaw-capital city with almost 2 million inhabitants. This is very promising phenomenon that almost $40 \%$ of our patients a performed test for HIV as their own decision. Our result can confirm the responsibility and awareness of young people in Poland. It should be 
noted the participation of other people in suggesting HIV testing - friends or a family member influenced this decision. Some of our patients had many risky contacts and performed more than one test for HIV. They informed their sexual partner rather than family. It is not a good situation that about $15 \%$ of our patients had not informed their partner at once after a positive HIV test but all informed their partner within 6 months. Most of our patients are HCV infected. In Poland about $80 \%$ HIV infected intravenous drug users (IDU) were coinfected with HCV in recent years [14]. Nowadays we registered a still high percentage of HIV/HCV but only among IDUs. In Poland we observed a decreasing number of newly HIV infected IDUs. In the last two years this was lower than $50 \%$ so we hope for a reduction of the HIV/HCV coinfection percentage [2]. Hospital, outpatients' clinics and PCDs were the most common places to perform tests for HIV. The main reason for HIV testing among our patients was risky sexual contact. In Poland we observed an increased number people testing in PCDs but the percentage of positive results among customers of PCDs slight increased in 2009 and 2010 remained stable at $1.22 \%$. In comparison to the structure of a nationwide picture among PCDs customers prevail: men, young people mostly 20 - 39 years. The majority of PCDs' customers are heterosexual. Among men 9.8\% were bisexual. Compared to previous years, there was an increase in the percentage of people who have performed the test more than once which is the same result as in our trial. More than 45\% of PCDs' customers maintain sexual contact with multiple partners and 3.3\% of HIV infected [11]. In our data connected to the length of HIV infection we get trace of changes in the epidemiology of HIV infection among Polish patients. The domination of IDU among those infected longer than 10 years and infected in sexual contacts in the last 6 years is a trend in the epidemiology of HIV infection in Poland during recent years.

\section{Conclusion}

In conclusion, because country's HIV prevalence with significant regional differences in epidemiologic trends is not stabilized, we suggest collecting epidemiological data of communities and analyzing all the data of our patients. This data gives new epidemiologic insights and can improve compliance with the patients.

\section{Conflict of Interest Statement}

None declared.

\section{References}

[1] Szata, W. (1989) Incidence of HIV Infection 1987-The Situation in Poland in Comparison with the World Situation. Przegląd Epidemiologiczny, 43, 115-123.

[2] Rosińska, M. (2013) HIV Infection and AIDS in Poland. Epidemiological Reports. Available at: https://www.pzh.gov.pl

[3] Marczyńska, M. and Szczepańska-Putz, M. (2000) Vertical Transmission of HIV-1 in Poland. Scandinavian Journal of Infectious Diseases, 32, 165-167.

[4] Kalayjian, R.C., Landay, A., Pollard, R.B., et al. (2003) Adult AIDS Clinical Trial Group 5015 Protocol Team, Adult AIDS Clinical Trial Group 5113 Protocol Team Age-related Immune Dysfunction in Health and in Human Immunodeficiency Virus (HIV) Disease: Association of Age and HIV Infection with Naive CD8+ Cell Depletion, Reduced Expression of CD28 on CD8+ Cells, and Reduced Thymic Volumes. The Journal of Infectious Diseases, 187, 1924-1933. http://dx.doi.org/10.1086/375372

[5] Naylor, K., Li, G., Vallejo, A.N., et al. (2005) The Influence of Age on T Cell Generation and TCR Diversity. The Journal of Immunology, 174, 7446-7452. http://dx.doi.org/10.4049/jimmunol.174.11.7446

[6] Niedźwiedzka-Stadnik, M. and Rosińska, M. (2012) HIV and AIDS in Poland in 2010. Przegląd Epidemiologiczny, 66, 315-323.

[7] Adler, A., Mounier-Jack, S. and Coker, R.J. (2009) Late Diagnosis of HIV in Europe: Definitional and Public Health Challenges. AIDS Care, 21, 284-293. http://dx.doi.org/10.1080/09540120802183537

[8] The National AIDS Centre (2012) Global AIDS Progress Reporting and Universal Access in the Health Sector Reporting and Dublin Declaration, Warsaw, 31 March 2012. Available at:

http://www.unaids.org/en/dataanalysis/knowyourresponse/countryprogressreports/2012countries/ce_PL_N arrative_Report.pdf

[9] UNAIDS Epidemiological Data. Available at: http://www.unaids.org/pub/epislides

[10] Rosińska, M. and Zieliński, A. (2011) Recent Increase in HIV Rate by Age, Cohort, and Period Analysis of Surveil- 
lance Data Suggests Changes in HIV Epidemiology in Poland. Central European Journal of Public Health, 19, 123-127.

[11] The Report of the Analysis of Questionnaires Filled in Consultative and diagnostic Points (PCDs) in 2010. Available at: http://www.aids.gov.pl/?page=badania\&act=res

[12] Czerwinski, M., McNutt, L.A., Dehovitz, J.A., Zielinski, A. and Rosinska, M. (2013) Refining HIV Risk: The Modifying Effects of Youth, Gender and Education among People Who Inject Drugs in Poland. PLoS One, 8, e68018. http://dx.doi.org/10.1371/journal.pone.0068018

[13] Rogowska-Szadkowska, D. and Chlabicz, S. (2011) Where and how do Polish patients contract HIV? Przeglad Epidemiologiczny, 65, 509-513.

[14] Touzet, S., Kraemer, L., Colin, C., et al. (2000) Epidemiology of Hepatitis C Virus Infection in Seven European Union Countries: A Critical Analysis of the Literature. HENCORE Group. Hepatitis C European Network for Co-operative Research. European Journal of Gastroenterology \& Hepatology, 12, 667-678.

http://dx.doi.org/10.1097/00042737-200012060-00017 